\title{
CORRELATION BETWEEN TUMOR EXTENT IN RADICAL PROSTATECTOMIES AND PREOPERATIVE PSA, HISTOLOGICAL GRADE, SURGICAL MARGINS, AND EXTRAPROSTATIC EXTENSION: APPLICATION OF A NEW PRACTICAL METHOD FOR TUMOR EXTENT EVALUATION
}

\author{
ATHANASE BILLIS, LUÍS A. MAGNA, UBIRAJARA FERREIRA \\ Departments of Pathologic Anatomy, Medical Genetics and Biostatistics, and Urology, \\ School of Medicine, State University of Campinas (UNICAMP), Campinas, São Paulo, \\ Brazil
}

\begin{abstract}
Purpose: To evaluate a new method designed for estimating the tumor extent in radical prostatectomy specimens. The tumor extent was correlated to preoperative PSA and to several pathologic findings in the surgical specimens as well.

Materials and Methods: Tumor extent was estimated in 118 consecutive radical prostatectomies through a simple point-count method. Drawn on a sheet of paper, each quadrant of the whole mount sections contained 8 equidistant points. During the microscopic slides examination, the tumor area was drawn over the correspondent quadrant of the paper sheet. According to the extent, tumors were classified in 5 groups: 1 ) very limited: $\leq 10$ positive points; 2 ) limited: 11-19 positive points; 3 ) moderately extensive: $20-35$ positive points; 4 ) extensive: $36-39$ positive points; 5) very extensive: 70 positive points. This classification was based on a previous analysis of tumor extent in 109 radical prostatectomies. The distribution was quite normal up to 69 positive points, but asymmetric above that number, including cases exceeding far above that value. We considered the quartiles of the normal distribution up to 69 positive points (groups 1 to 4), and above that value a fifth group was considered.

Results: There was a statistically significant and direct correlation between the tumor extent and all variables studied: preoperative PSA $(p=0.03)$, Gleason score $(p<0.0001)$, primary grade in high-grade tumors $(\mathrm{p}<0.01)$, surgical margins $(\mathrm{p}<0.0001)$, extraprostatic extension (pT3a) $(\mathrm{p}<0.0001)$, and seminal vesicle invasion (pT3b) $(\mathrm{p}=0.01)$.

Conclusions: The method, which is simple and well correlated to other prognostic factors, is accessible to those pathologists working in routine pathology laboratories. Whether this method will be used by other urology centers is yet to be seen.
\end{abstract}

Key words: prostate; prostatic neoplasms; pathology; classification

Int Braz J Urol. 2003; 29: 113-20

\section{INTRODUCTION}

Tumor volume correlates to adverse findings at radical prostatectomy, such as the Gleason score, the margins of resection, the pathologic stage, and the progression following surgery $(1,2)$. A problem for evaluating this correlation is related to the measurement of the tumor volume in radical prostatectomies. There is no acknowledged standard for reporting the cancer volume in prostatectomy specimens (3). 
Some institutions have accurately calculated the tumor volume through computer-assisted image analysis systems (2). As this method is not feasible for the routine clinical practice, other investigators have proposed alternative simpler means for measuring the tumor volume (4-7).

In this study, we applied and are proposing a practical method for estimating the tumor extent in radical prostatectomy specimens, which can be used by any general pathologist in the laboratory. The tumor extent was correlated to preoperative PSA and also to several pathologic findings in the surgical specimens.

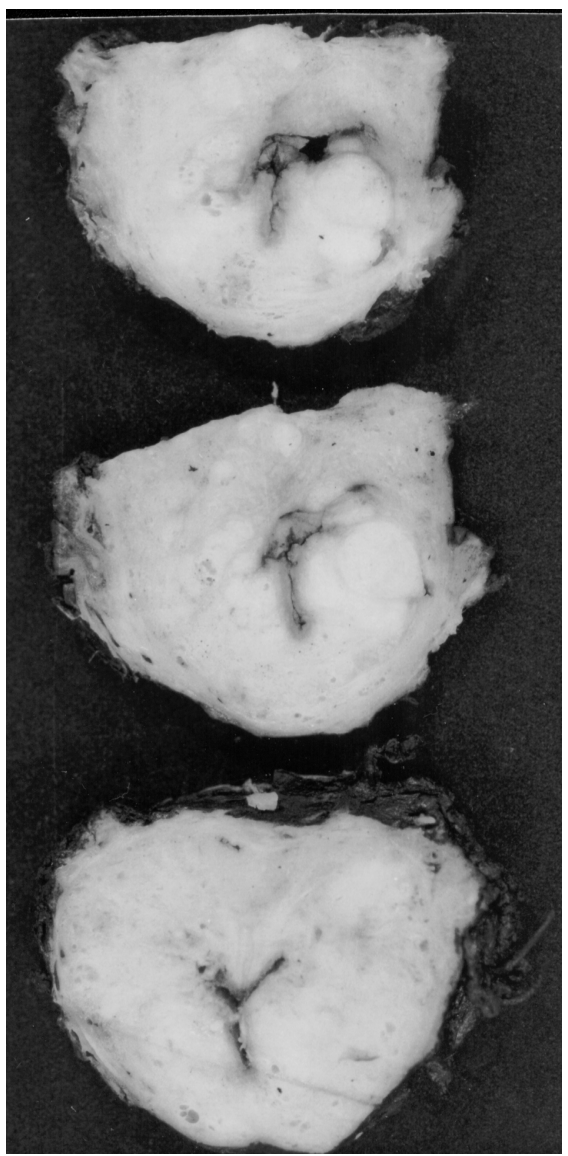

Figure 1 - The previously fixed surgical specimen was weighed, measured, and the entire surface inked. The bladder neck and apical margins were amputated. From each cone-shaped amputated margin, 8 fragments were processed through perpendicular sections relative to the margins. The rest of the prostate was serially cut in transverse sections at 3 to $5 \mathrm{~mm}$ intervals, as shown.

\section{MATERIALS AND METHODS}

The material was obtained from 118 consecutive patients submitted to radical prostatectomy.

The previously fixed surgical specimen was weighed, measured, and the entire surface was covered by Nankin ink. The bladder neck and the apical margins were amputated. From each cone-shaped amputated margin, 8 fragments were processed through sections perpendicular to the margins. The rest of the prostate was serially cut in 3 to $5 \mathrm{~mm}$ transverse sections intervals (Figure-1). The prostate slices were subdivided into quadrants and labeled to allow for reconstruction as whole-mount sections (Figure-2).

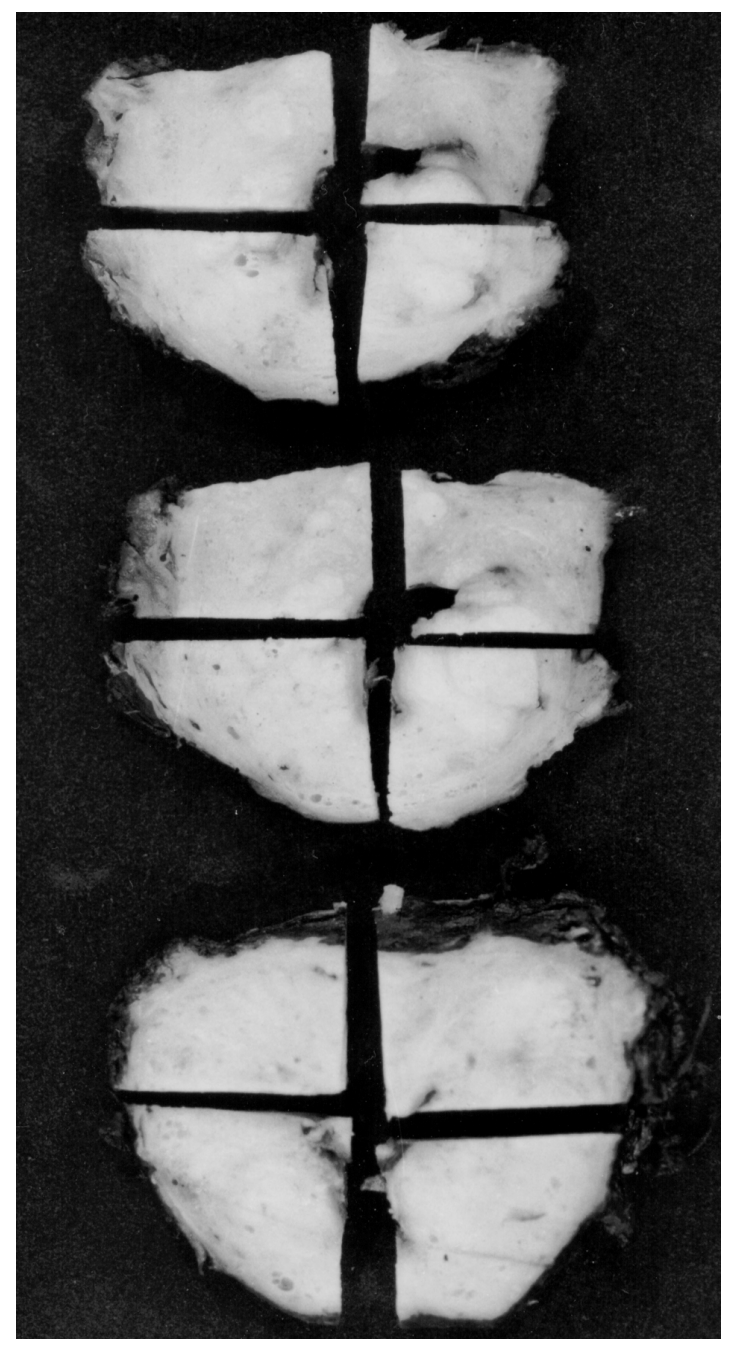

Figure 2 - The prostate slices were subdivided into quadrants and labeled to allow for reconstruction as whole-mount sections. 
Blocks were embedded in paraffin, cut at 6 $\mu \mathrm{m}$, and one section from each block was stained with hematoxylin and eosin. The presence of adenocarcinoma was diagnosed according to the Mostofi \& Price (8) criteria. The diagnosis was based on either invasion or architectural disturbance. The histological grading was performed according to the Gleason system (9). Prostatic carcinomas with final score 2-6 were considered low-intermediate grade; and the ones with final score 7-10 were considered high-grade (10). Highgrade tumors were subdivided into 2 groups: A) with primary grade $3 ; \mathrm{B}$ ) with primary grade 4 to 5 .

The tumor extent was estimated by the use of a point-count method. Drawn on a sheet of paper, each quadrant of the whole mount sections contained 8 equidistant points. During the microscopic examination of the slides, the tumor area was drawn over the corresponding quadrant seen on the paper sheet (Figure-3). At the end of the examination, the amount of positive points represented an estimate of the tumor extent.
According to the extent, tumors were classified in 5 groups: 1) very limited: $\leq 10$ positive points; 2) limited: 11-19 positive points; 3 ) moderately extensive: $20-35$ positive points; 4) extensive: $36-69$ positive points; 5) very extensive: $\geq 70$ positive points.

This classification was based on a previous tumor extent analysis performed in 109 radical prostatectomies. The number of positive points in these 109 specimens ranged from 0 to 225 (mean $=34$ and median $=26$ positive points). The distribution was quite normal up to 69 positive points, but asymmetric above that number, presenting cases exceeding far above that value (Figure-4). Considering this kind of distribution, the best stratification was to consider the quartiles of normal distribution up to 69 positive points (Figure-5) and a fifth group above that value.

The seminal vesicle invasion was defined as an invasion of the muscular wall, as described by Epstein et al. (11), corresponding to pT3b in the TNM system (12). The extraprostatic extension was diagnosed according to Bostwick \& Montironi (13),

Table 1 - Correlation of tumor extent evaluated by distribution of positive points to preoperative PSA, Gleason score, primary Gleason grade, surgical margins, extraprostatic extension (pT3a) and seminal vesicle invasion (pT3b).

\section{Groups According to Tumor Extent (Positive Points)}

\begin{tabular}{lcccccc} 
Variable & $\mathbf{1}(\mathbf{1 0})$ & $\mathbf{2 ( 1 1 - 1 9 )}$ & $\mathbf{3}(\mathbf{2 0 - 3 5 )}$ & $\mathbf{4}(\mathbf{3 6}-\mathbf{6 9})$ & $\mathbf{5}(\mathbf{2} \mathbf{7 0})$ & $\mathbf{p}$ \\
\hline PSA $\leq 10$ & $18(24.32 \%)$ & $13(17.56 \%)$ & $24(32.43 \%)$ & $14(18.91 \%)$ & $05(6.75 \%)$ & 0.03 \\
PSA $>10$ & $06(13.95 \%)$ & $08(18.60 \%)$ & $07(16.27 \%)$ & $12(27.90 \%)$ & $10(23.25 \%)$ & \\
LG & $19(43.18 \%)$ & $11(25 \%)$ & $09(20.45 \%)$ & $05(11.36 \%)$ & 0 & $<0.0001$ \\
HG & $04(5.55 \%)$ & $10(13.88 \%)$ & $22(30.55 \%)$ & $21(29.83 \%)$ & $15(20.83 \%)$ & \\
HG $(3)$ & $02(3.44 \%)$ & $09(15.51 \%)$ & $22(37.93 \%)$ & $17(29.31 \%)$ & $08(13.79 \%)$ & $<0.01$ \\
HG $(4$ or 5) & $02(14.28 \%)$ & $01(7.14 \%)$ & 0 & $04(28.57 \%)$ & $07(50 \%)$ & \\
M- & $23(32.85 \%)$ & $14(20 \%)$ & $17(24.28 \%)$ & $13(18.57 \%)$ & $03(4.28 \%)$ & $<0.0001$ \\
M+ & $01(2.08 \%)$ & $08(16.66 \%)$ & $14(29.16 \%)$ & $13(27.08 \%)$ & $12(25 \%)$ & \\
EPE- & $23(26.13 \%)$ & $21(23.86 \%)$ & $24(27.27 \%)$ & $14(15.90 \%)$ & $06(6.81 \%)$ & $<0.0001$ \\
EPE+ & $01(3.33 \%)$ & $01(3.33 \%)$ & $07(23.33 \%)$ & $12(40 \%)$ & $09(30 \%)$ & \\
SV- & $23(21.69 \%)$ & $22(20.75 \%)$ & $29(27.35 \%)$ & $21(19.81 \%)$ & $11(10.37 \%)$ & 0.01 \\
SV+ & 0 & 0 & $01(18.18 \%)$ & $05(45.45 \%)$ & $04(36.36 \%)$ &
\end{tabular}

$\overline{P S A}=$ prostate specific antigen $; L G=$ Gleason low-intermediate grade; $H G=$ Gleason high-grade; HG $(3)=G l e a s o n$ high-grade with primary grade 3; HG (4 or 5) = Gleason high-grade with primary grade 4 or $5 ; M-=$ negative surgical margin; $M+=$ positive surgical margin; EPE- = absence of extraprostatic extension; $E P E+=$ presence of extraprostatic extension; SV- = absence of seminal vesicle invasion; $S V+=$ presence of seminal vesicle invasion. 

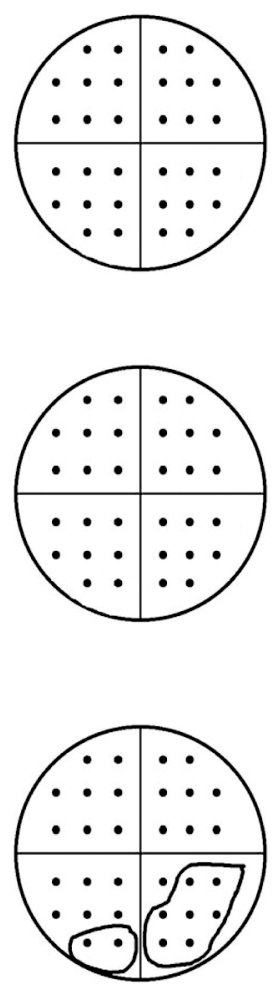

Figure 3 - Sheet of paper showing 3 transversal whole sections of a prostate and 12 quadrants each one with 8 equidistant points in a total of 96 points. Tumor extent corresponds to 9 positive points.

whenever cancer was seen in adipose tissue, and corresponds to $\mathrm{pT} 3 \mathrm{a}$ in the TNM system. The positive surgical margins (bladder, urethral or lateral) were defined as cancer cells touching the inked surface of the prostate.

The data were statistically analyzed by the qui-square test and Fisher's exact test for evaluating the differences between proportions. $\mathrm{P}$ value $\geq 0.05$ was considered statistically significant.

\section{RESULTS}

The results are shown in the Table-1. There were no information regarding preoperative PSA in
1 patient, seminal vesicle invasion in 1 patient, and Gleason score in 2 patients. Therefore, the data concerning the former variables in the Table- 1 correspond to 117,117 and 116 patients, respectively.

From a total of 72 radical prostatectomies with high-grade Gleason score, 58 had primary grade 3 and 14 had primary grade 4 or 5 .

The number of slices examined for each prostate ranged from 3 to 14 (mean $=8)$ and the number of quadrants from 12 to $56($ mean $=32)$. The number of total points for each prostate ranged from 96 to $448($ mean $=255)$ and the positive points from 0 to $368($ mean $=35)$.

\section{DISCUSSION}

One of the most controversial aspects of the pathologic assessment of radical prostatectomy specimens is the measurement of the tumor volume (2). Nevertheless, as yet, there are no defined standards for reporting the cancer volume in prostatectomy specimens (3).

Some institutions have calculated the tumor volume accurately, using computer-assisted image analysis systems. Because this method is not feasible for the routine clinical practice, other investigators have proposed alternative simpler means for measuring tumor volume, including the diameter of largest tumor focus, the number of tumor foci, the number of involved blocks, the percentage of blocks involved, the use of a $3.0 \mathrm{~mm}$ squares grid, or naked eye examination of the glass slides after the pathologist had circled all microscopically identifiable foci of carcinoma with a marking pen (the pathologist's percentage estimate) $(4-7,14,15)$.

The method for evaluating tumor extent applied and proposed in this study is simple and accessible to all pathologists. There is no need for special device, except the drawing on a sheet of paper. It is not time consuming, because the pathologist draws the proportional area seen on the microscopic field on the sheet of paper while he examines the slides. Considering that only a visual estimate of the tumor extent provides an important prognostic information after radical prostatectomy (15), our method is supe- 


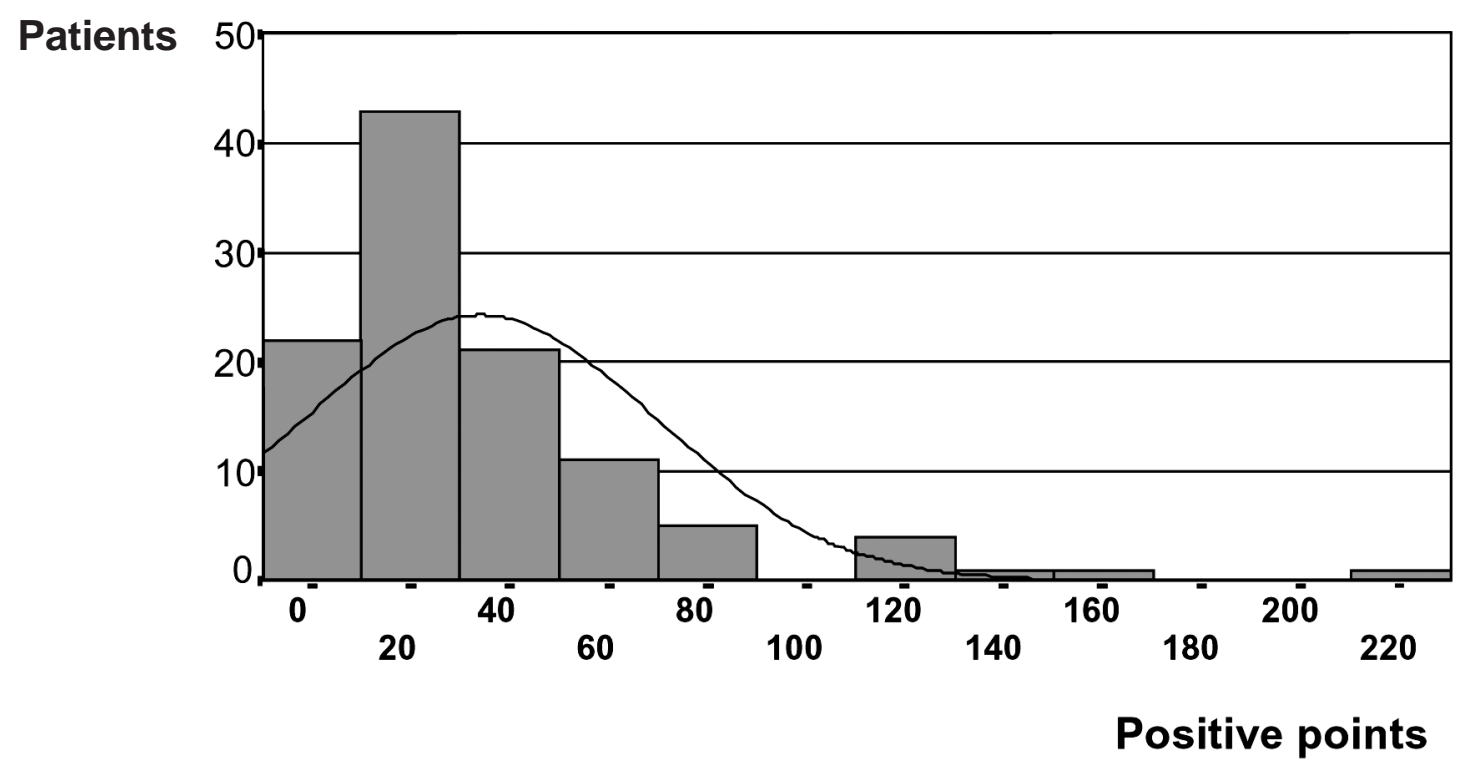

Figure 4-Distribution of positive points in 109 patients submitted to radical prostatectomy.

rior, because it includes a point-count method represented by the 8 equidistant points in each quadrant of the whole-mount transverse sections. According to the stereological principle, the distribution by area is proportional to the volume distribution, when the considered region is homogeneous.

\section{Patients}

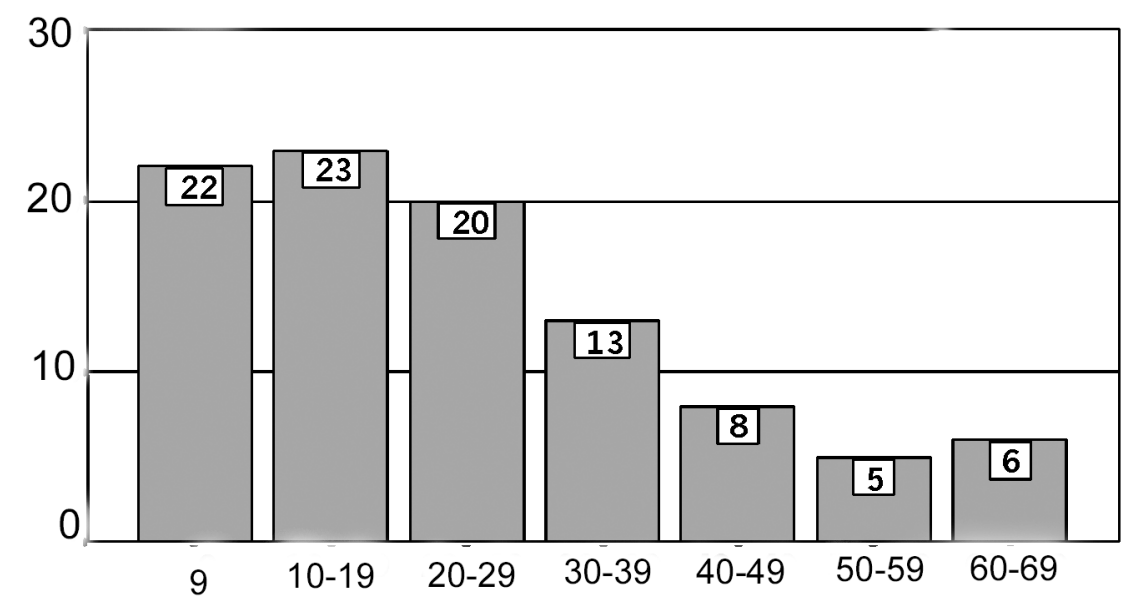

\section{Positive points}

Figure 5 - Distribution of positive points up to a value of 69 in 97 patients submitted to radical prostatectomy. 
A number of studies have documented that the tumor extent, the volume and the percentage of prostatic tissue involved by the tumor within the prostate gland are important prognostic indicators. The tumor extent has been correlated to histological grade, clinicopathologic stage, tumor progression, and patient survival rate $(14,16)$. The tumor volume has been related to metastasis, seminal vesicle invasion, capsule invasion, histological differentiation, and prognosis $(14,17-20)$. The percentage of prostatic tissue involved by tumor seemed to exhibit a stronger association with pathologic stage and tumor progression than with tumor volume $(18,19)$.

In our study, there was a statistically significant and direct correlation of tumor extent to all variables studied: preoperative PSA ( $p=0.03$ ), Gleason score $(p<0.0001)$, surgical margins $(p<0.0001)$, extraprostatic extension (pT3a) $(\mathrm{p}<0.0001)$ and seminal vesicle invasion ( $\mathrm{pT} 3 \mathrm{~b})(\mathrm{p}=0.01)$. A noteworthy finding was the correlation of extent to the primary grade in high-grade tumors. High-grade tumors with a primary grade 4 or 5 were significantly more extensive than tumors with a primary grade 3 $(p<0.01)$. Recent studies have shown that Gleason score $4+3$ and Gleason $3+4$ are different in pathological parameters and prognosis $(21,22)$.

Although most authors agree that tumor size (percentage of carcinoma or tumor volume) in patients with prostate carcinoma should be reported in radical prostatectomies because of its prognostic importance, in some analyses, tumor size has not been considered to be an independent predictor of tumor recurrence $(2,23)$. Due to the simplicity and accessibility of the method proposed in the present study, we believe that more urologic centers will be able to apply it and present data on the extent versus tumor recurrence controversy.

\section{CONCLUSIONS}

Tumor extent in radical prostatectomies correlated to preoperative PSA, Gleason score, primary Gleason grade, surgical margins and extraprostatic extension (pT3a and pT3b). The method for tumor extent evaluation applied and proposed in this study is a simple one and accessible to all general pathologists working in routine pathology laboratories. Whether this method will be used by more urologic centers is yet to be seen.

\section{REFERENCES}

1. McNeal JE: Cancer volume and site of origin of adenocarcinoma in the prostate: relationship to local and distant spread. Hum Pathol. 1992; 23: 258-66.

2. Epstein JI: Pathologic assessment of the surgical specimen. Urol Clin North Am. 2001; 28: 567-94.

3. Bostwick DG, Montironi R: Evaluating radical prostatectomy specimens: therapeutic and prognostic importance. Virchows Arch. 1997; 430: 1-16.

4. Cantrell BB, DeKlerk DP, Eggleston JC, Boitnott JK, Walsh PC: Pathologic factors that influence prognosis in stage A prostatic cancer: The influence of extent versus grade. J Urol. 1981; 125: 516-20.

5. Humphrey PA, Vollmer RT: Percentage carcinoma as a measure of prostatic tumor size in radical prostatectomy tissues. Mod Pathol. 1997; 10: 32633.

6. Renshaw AA, Chang H, D'Amico AV: Estimation of tumor volume in radical prostatectomy specimens in routine clinical practice. Am J Clin Pathol. 1997; 107: 704-8.

7. Renshaw AA, Richie JR, Loughlin KR, Jiroutek M, Chung A, D'Amico AV: Maximum diameter of prostatic carcinoma is a simple, inexpensive, and independent predictor of prostate-specific antigen failure in radical prostatectomy specimens. Am J Clin Pathol. 1999; 111: 641-4.

8. Mostofi FK, Price EB Jr: Tumors of the Male Genital System, Atlas of Tumor Pathology, Second Series, Fascicle 8. Washington DC, Armed Forces Institute of Pathology. 1973; pp. 202-17.

9. Gleason DF, Mellinger GT and the Veterans Administration Cooperative Urological Research Group: Prediction of prognosis for prostatic adenocarcinoma by combined histological grading and clinical staging. J Urol. 1974; 111: 58-64.

10. Gleason DF: Histologic grading of prostate cancer: A perspective. Hum Pathol. 1992; 23: 273-9.

11. Epstein JI, Carmichael M, Walsh PC: Adenocarcinoma of the prostate invading the seminal vesicle: definition and relation of tumor volume, grade and margins of resection to prognosis. J Urol. 1993; 149: 1040-5. 
12. International Union Against Cancer: Prostate. In: Sobin LH, Wittekind Ch. (eds.), TNM Classification of Malignant Tumors, $6^{\text {th }}$ ed. New York, Wiley-Liss. 2002; pp. 184-7.

13. Bostwick DG, Montironi E: Evaluating radical prostatectomy specimens: therapeutic and prognostic importance. Virchows Arch. 1997; 430: 1-16.

14. Humphrey PA, Vollmer RT: Intraglandular tumor extent and prognosis in prostatic carcinoma: Application of a grid method to prostatectomy specimens. Hum Pathol. 1990; 21: 799-804.

15. Carvalhal GF, Humphrey PA, Thorson P, Yan Y, Ramos CG, Catalona WJ: Visual estimate of the percentage of carcinoma is an independent predictor of prostate carcinoma recurrence after radical prostatectomy. Cancer. 2000; 89: 1308-14.

16. Humphrey A, Vollmer RT: The ratio of prostate chips with cancer: A new measure of tumor extent and its relationship to grade and prognosis. Hum Pathol. 1988; 19: 411-8.

17. McNeal JE, Bostwick DG, Kindrachuk RA, Redwine EA, Freiha FS, Stamey TA: Patterns of progression in prostate cancer. Lancet 1986; 1: 60-3.

18. Epstein JI, Oesterling JE, Walsh PC: Tumor volume versus percentage of specimen involved by tumor correlated with progression in stage A prostatic carcinoma. J Urol. 1988; 139: 980-4.
19. Partin AW, Epstein JI, Cho KR, Gillelsohn AM, Walsh PC: Morphometric measurement of tumor volume and per cent of gland involvement as predictors of pathological stage in clinical stage B prostate cancer. J Urol. 1989; 141: 341-5.

20. McNeal JE, Price HM, Redwine EA, Freiha FS, Stamey TA: Stage A versus stage B adenocarcinoma of the prostate: Morphological comparison and biological significance. J Urol. 1988; 139: 61-5.

21. Herman CM, Kattan MW, Ohori M, Scardino PT, Wheeler TM: Primary Gleason pattern as a predictor of disease progression in Gleason score 7 prostate cancer: a multivariate analysis of 823 men treated with radical prostatectomy. Am J Surg Pathol. 2001; 25: 657-60.

22. Lau WK, Blute ML, Bostwick DG, Weaver AL, Sebo TJ, Zincke H: Prognostic factors for survival of patients with pathological Gleason score 7 prostate cancer: differences in outcome between primary Gleason grades 3 and 4. J Urol. 2001; 166: 1692-7.

23. Epstein JI, Carmichael M, Partin AW, Walsh PC: Is tumor volume an independent predictor of progression following radical prostatectomy? A multivariate analysis of 185 clinical stage B adenocarcinoma of the prostate with 5 years of follow-up. J Urol. 1993; 149: 1478-85.

Received: November 13, 2003 Accepted after revision: February 19, 2003

\author{
Correspondence address: \\ Dr. Athanase Billis \\ Faculdade de Ciências Médicas - UNICAMP \\ Departamento de Anatomia Patológica \\ Caixa Postal 6111 \\ Campinas, SP, 13083-970, Brazil \\ Fax: + 5519 3289-3897 \\ E-mail: athanase@fcm.unicamp.br
}




\section{EDITORIAL COMMENT}

Tumor size in radical prostatectomy specimens is an important prognostic indicator, since prostatic carcinoma size has been linked to a number of pathological and clinical variables such as Gleason score, pathologic stage, PSA level, response to therapy and risk of death due to prostatic carcinoma. Several methods have been proposed for quantification of tumor size, including simple visual inspection, measurement of the diameter of the largest focus, grid technique and computer-assisted morphometric measurements, but some of these methods are time consuming, expensive and are not available at all hospitals. For routine daily practice, a rough microscopic visual inspection estimation of the percentage of the prostatic parenchyma that is involved by carcinoma can be provided.

In this study, the authors propose a practical method for estimating tumor extent that can be used by general pathologists in their laboratories due to its simplicity, accessibility and reproducibility. The authors note that tumor size is correlated with preoperative PSA, Gleason score, primary grade in highgrade tumors, surgical margins, extraprostatic extension and seminal vesicle invasion, and reporting this parameter is recommended.

\section{Dr. Carlos Álvarez-Álvarez Department of Pathology Policlínica de Vigo Vigo, Spain}

